\title{
Experimental Determination of Heat Transfer Coefficients During Squeeze Casting of Aluminium
}

\author{
Jacob O. Aweda and Michael B. Adeyemi \\ Additional information is available at the end of the chapter
}

http://dx.doi.org/10.5772/52038

\section{Introduction}

Casting process is desired because it is very versatile, flexible, and economical and happens to be the shortest and fastest way to transform raw material into finished product. Squeeze casting belongs to permanent mould casting method which offers considerable saving in cost for large production quantities when the size of the casting is not large. Squeeze casting has the advantage of producing good surface finish, close dimensional tolerance and the absence of sand inclusions on the cast surfaces of the products as opined by Das and Chatterjee, (1981).

The solidification process of the molten aluminium metal in the steel mould takes a complex form, (Hosford and Caddell, 1993) and (Potter and Easterling, 1993). During solidification all mechanisms of heat transfer are involved and the solidifying metal undergoes state and phase changes. The final structure and properties of the cast product obtained depend on the casting parameters applied i.e. applied pressures, die pre-heat temperature, delay time and period of applied pressure on the solidifying metal, (Potter and Easterling, 1993), (Bolton, 1989) and (Callister, 1997). The prediction of temperature distribution and solidification rate in metal casting is very important in modern foundry technologies. This helps to control the fundamental parameters such as the occurrence of defects, as well as, the influence on final properties of cast products and the mould wall / cast metal interface contact surface.

Heat transfer coefficients during squeeze cast of commercial aluminium were determined using the solidification temperature versus time curves obtained for varying applied pressures during squeeze casting process. The steel mould / cast aluminium metal interface temperatures versus times curve obtained through polynomial curves fitting and 
extrapolation was compared with the numerically obtained temperatures versus times curve. Interfacial heat transfer coefficients were determined experimentally from measured values of heating and cooling temperatures of steel mould and cast metal and compared with the numerically obtained values and found to be fairly close in values.

Aluminium is a product with unique properties, making it a natural partner for the building and other manufacturing industries. The commercially pure aluminium metal used for this research work finds extensive use in the building, manufacturing and process industries, both as a material of construction and household goods. Products of squeeze casting are of improved mechanical properties and could be given heat treatment. Heat dissipation from the squeeze cast specimen is fast thus producing products of fine grains as compared to the slow cooling of sand casting, which produces large grains. Products obtained through squeeze casting are with improved mechanical properties.

\section{Squeeze casting procedure}

A metered quantity of molten metal was poured into the steel mould cavity at a supper-heat temperature of between $40-60{ }^{\circ} \mathrm{C}$ fast but avoiding turbulence. The upper die was then released to close the mould cavity with and without applying any load on the upper die. Thermocouples were inserted into the drilled holes made in the die, which were used to monitor both the die and cast metal temperatures. The terminals of the thermocouples were connected to the chart recorder/plotter (set at the highest speed of $10 \mathrm{~mm} / \mathrm{s}$ and voltage $100 \mathrm{mV}$ ) through the cold junction apparatus, maintained at $0{ }^{\circ} \mathrm{C}$ throughout the measuring period.

\section{Assumptions made}

i. Heat transfer in the molten metal cast zone is due to both conduction and convection while conduction heat transfer occurs in the steel mould, it is convection at the outer surface of the steel mould.

ii. The thickness of the cast specimen is much smaller than the diameter (radial dimension), thus giving one dimensional heat transfer process.

iii. Considering the symmetrical nature of the cast specimen, solidification process was assumed symmetrical and only lower half of the specimen's thickness was analysed see figure 1 .

iv. The bottom of the squeeze casting rig was and the heat losses to the atmosphere was small and neglected.

v. Heat losses through conduction and convection to the atmosphere at the punch were neglected, as a result of short time of pressure application.

vi. The process of analyses in the cast specimen starts only when the steel mould cavity had been filled with the required quantity of liquid molten metal (i.e. heat transfer processes during pouring of molten aluminium into the steel mould are not considered).

vii. Density of the molten and solidified aluminium metal was assumed to be the same and independent of temperature. 
viii. Thermal conductivity and specific heat of aluminium metal were dependent on the cast temperatures.

\section{Heat transfer governing equations}

\subsection{Without pressure application on the cast metal}

A measured quantity of molten aluminium metal was poured into the steel mould cavity. The process of solidification begins from the steel mould/cast metal interface and continues inwards into the cast metal. As this process continues, there was an increase in the thickness of the solidified layer and a decrease in the liquid molten metal portion. For the situation when no pressure was applied on the solidified molten metal, the governing heat transfer equations in one dimension are given by equation (1).

$$
\rho C \frac{\partial T}{\partial t}=K\left[\frac{\partial^{2} T}{\partial r^{2}}+\frac{1}{r} \frac{\partial T}{\partial r}\right]
$$

From figure 1, equation (1) is defined within the region with;

i. Steel mould,

$$
L \leq r_{s t} \leq(L+Q)
$$

ii. Solidified molten,

$$
\begin{gathered}
\left(L-X_{r}^{j}\right) \leq r_{S} \leq L \\
T_{S}=T_{M M}=660\left({ }^{0} C\right)
\end{gathered}
$$

iii. Liquid molten metal,

$$
\begin{gathered}
0 \leq r_{L} \leq\left(L-X_{r}^{j}\right) \\
K_{S} \frac{\partial T_{S}}{\partial r}=0 \\
r=0 \\
T_{L}=T_{P}=720\left({ }^{0} C\right)
\end{gathered}
$$

iv. At the phase change boundary condition;

$$
\rho_{L} L_{f} \frac{d X_{r}^{j}}{d t}=K_{L} \frac{\partial T_{L}}{\partial r}-K_{S} \frac{\partial T_{S}}{\partial r}
$$


where,

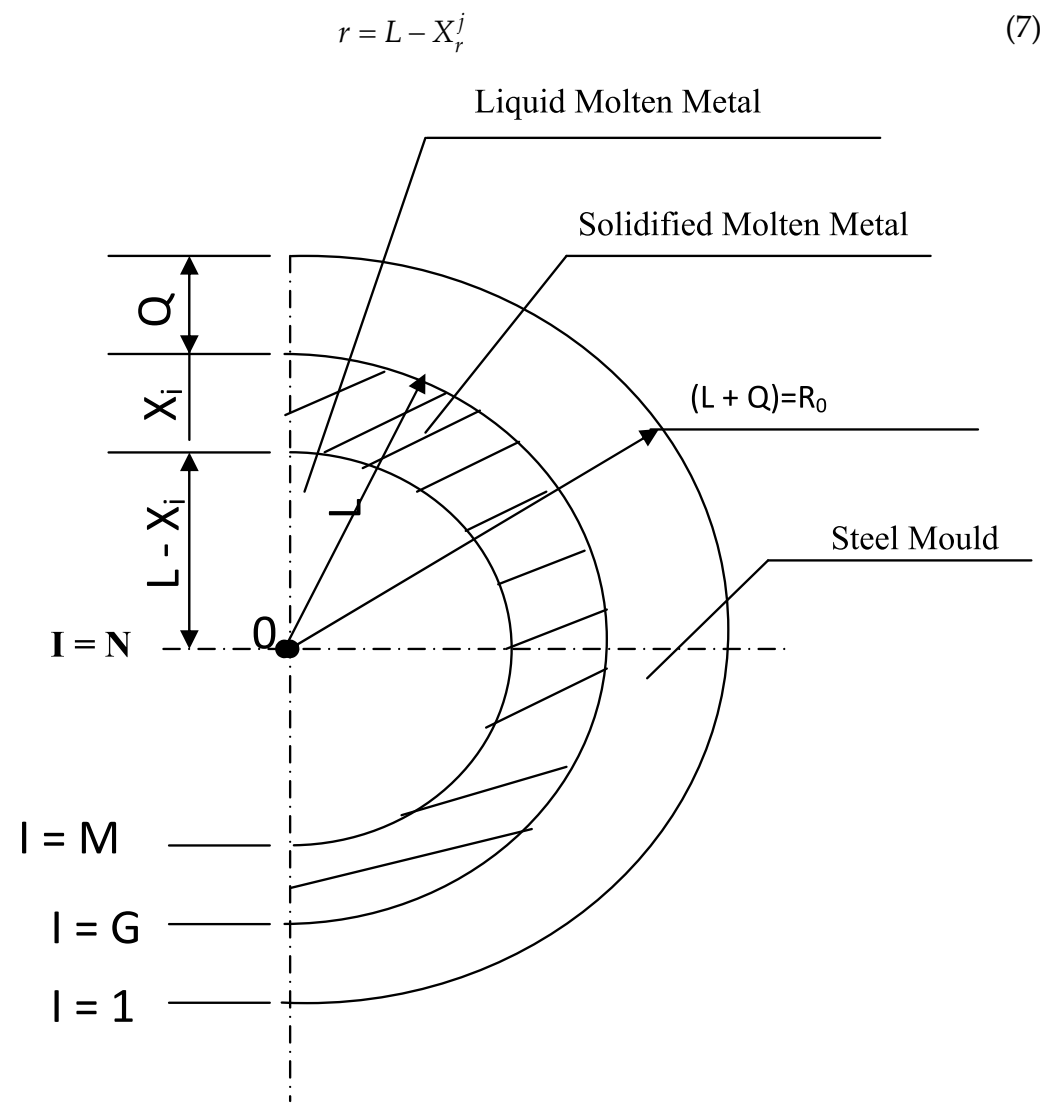

Figure 1. Schematic representation of solidification front in one dimension (radial direction)

\subsection{Casting with pressure application on the solidified molten metal}

As the cast aluminium metal solidifies, pressure is applied on the specimen, observing lapse or delay time, $t$, while varying the values of pressure applied. The time between the end of pouring of molten metal and pressure application known as lapse time, is recorded. This is necessary such that the cast specimen will not stick to the upper punch or cause the cast metal to tear with pressure application. Due to the applied pressure, an internal energy $\Delta \mathrm{q}$ is generated within the solidified molten metal, (see figure 2).

Inserting the internal energy into the heat transfer equation (1) for solidified molten metal, it becomes equation (8),

$$
\rho_{S} C_{S} \frac{\partial T_{S}}{\partial t}=K_{S}\left[\frac{\partial^{2} T_{S}}{\partial r^{2}}+\frac{1}{r_{S}} \frac{\partial T_{S}}{\partial r}\right]+\Delta q
$$


where,

$$
\nabla q=\nabla q_{P}+\nabla q_{f}
$$

$\Delta \mathrm{q} \quad$-internal energy generated by applied pressure,

$\Delta \mathrm{q} \quad \quad$-energy due to plastic strain within the solidified molten metal material,

$\Delta \mathrm{q}_{\mathrm{f}} \quad$-frictional energy generated during pressure application,

$$
\nabla q_{f}=\nabla q_{f P}+\nabla q_{f m}
$$

$\Delta \mathrm{qfP}_{\mathrm{fP}} \quad$-frictional energy due to punch / solidified molten metal interface,

$\Delta \mathrm{q}_{\mathrm{fm}} \quad$-frictional energy due to steel mould cylindrical surface / solidified molten metal interface.

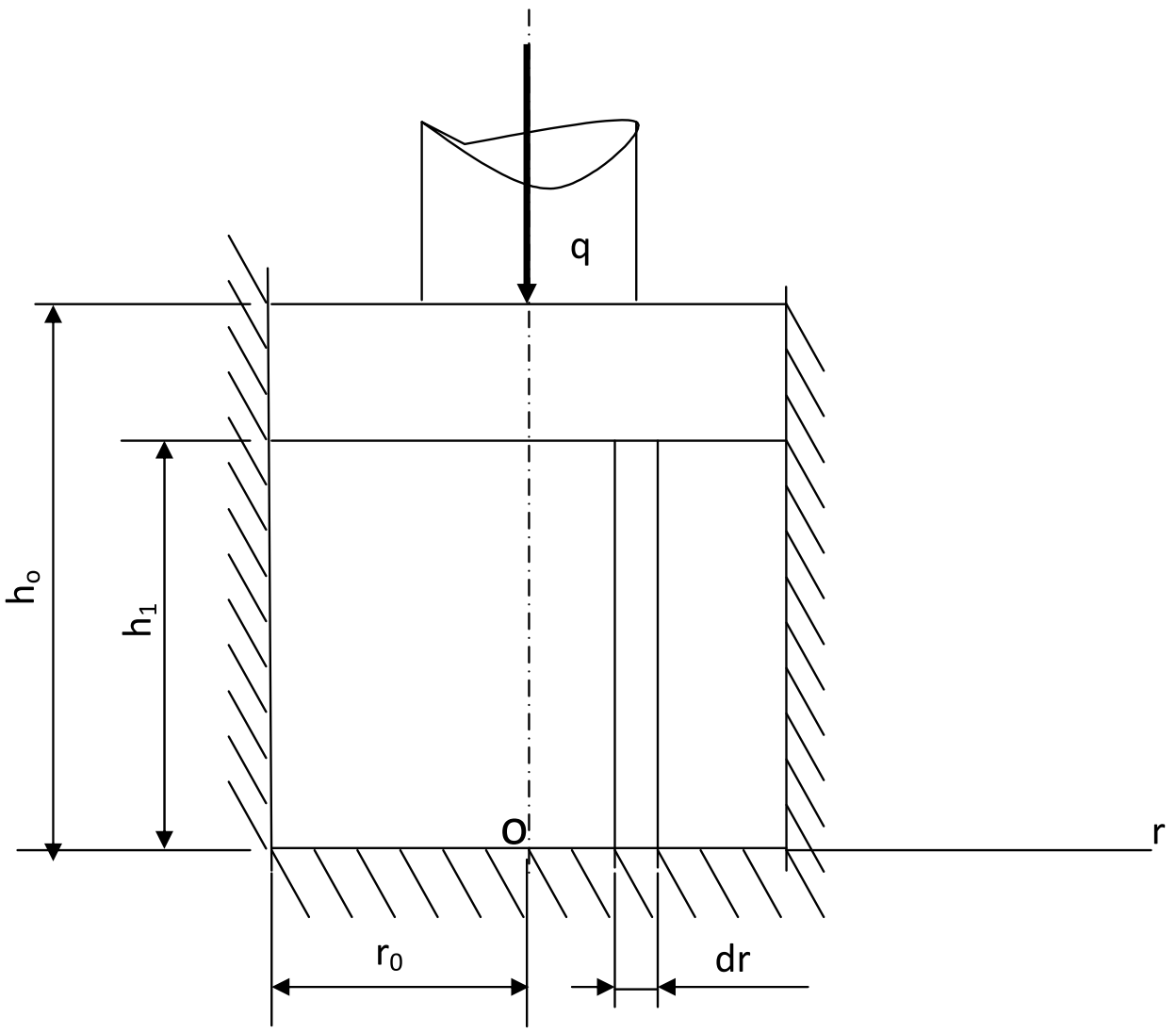

Figure 2. Cast specimen under pressure 


\section{Formulation of heat transfer equations}

Finite difference expressions for the nodal temperatures are obtained by either energy balance within an elemental volume around the node or by substitutions into the governing partial differential equations. Partial time derivative of temperature contained in the equations can be written in terms of a moving gradient as in White (1991) at a velocity of $\mathrm{dx} / \mathrm{dt}$. In the heat transfer equation, temperature is defined as a function of distance, $\mathrm{r}$ with time, $t$ and represented in equation (11).

$$
T=T(r, t)
$$

\subsection{In the steel mould}

$$
\frac{d T_{s t}}{d t}=\alpha_{s t} \frac{\partial^{2} T_{s t}}{\partial r^{2}}+\frac{\alpha_{s t}}{r_{s t}} \frac{\partial T_{s t}}{\partial r}
$$

where,

$$
\begin{gathered}
\frac{d r_{s t}}{d t}=0 \\
\alpha_{s t}=\frac{K_{s t}}{\rho_{s t} C_{s t}}
\end{gathered}
$$

$\alpha_{\text {st }}$-thermal diffusivity of steel mould material.

\subsection{In the solidified molten metal}

$$
\frac{d T_{S}}{d t}-\frac{(I-G)}{(M-G)} \frac{d X_{i}^{r}}{d t} \frac{\partial T_{S}}{\partial r}=\alpha_{S} \frac{\partial^{2} T_{S}}{\partial r^{2}}+\frac{\alpha_{S}}{r_{S}} \frac{\partial T_{S}}{\partial r}
$$

where,

$$
\alpha_{S}=\frac{K_{S}}{\rho_{S} C_{S}}
$$

as -thermal diffusivity of solidified molten metal material.

\subsection{In the liquid molten metal}

$$
\frac{d T_{L}}{d t}-\frac{(I-M)}{(N-M)} \frac{d X_{i}^{r}}{d t} \frac{\partial T_{L}}{\partial r}=\alpha_{L} \frac{\partial^{2} T_{L}}{\partial r^{2}}+\frac{\alpha_{L}}{r_{L}} \frac{\partial T_{L}}{\partial r}
$$

where, 


$$
\alpha_{L}=\frac{K_{L}}{\rho_{L} C_{L}}
$$

$\alpha_{\mathrm{L}}$-thermal diffusivity of liquid molten metal material.

\section{Nodal divisions}

The steel mould, the solidified metal and the molten metal regions were discretized separately. Each of these regions was divided into a fixed number of gridal points as in figure 1 .

\subsection{In the steel mould}

$$
d_{s t}=\frac{Q}{(G-I)}
$$

$\mathrm{I}=1,2,3, \ldots, \mathrm{G}-1$

\subsection{In the solidified molten metal}

$$
d_{S}=\frac{X_{r}^{i}}{(M-I)}
$$

$\mathrm{I}=\mathrm{G}+1, \mathrm{G}+2, \mathrm{G}+3, \ldots, \mathrm{M}-1$

\subsection{In the liquid molten metal portion}

$$
d_{L}=\frac{\left(L-X_{r}^{i}\right)}{(N-I)}
$$

$\mathrm{I}=\mathrm{M}+1, \mathrm{M}+2, \mathrm{M}+3 \ldots \mathrm{N}-1$

\subsection{In the phase change boundaries}

The phase change is represented by the equations;

$$
\begin{gathered}
d_{P S}=\frac{X_{r}^{i}}{(M-G)} \\
d_{P L}=\frac{\left(L-X_{r}^{i}\right)}{(N-M)}
\end{gathered}
$$




\subsection{At the completion of solidification}

$$
d_{S C}=\frac{L}{(N-G)}
$$

As solidification time progresses, the boundary locations change, and the thickness of the solidified molten metal in the radial direction increases. The rate of change of boundary location with time is represented, mathematically in equation (25),

$$
\frac{d X_{r}^{i}}{d t}=\frac{\left(X_{r}^{j+1}-X_{r}^{j}\right)}{\delta}
$$

Where,

$\left(X_{r}^{j+1}-X_{r}^{j}\right)$-are differences in the thickness of solidified molten metal at a particular time interval as time progresses in the radial direction.

$\delta$-time interval.

\section{Boundary conditions}

The problem of phase change during solidification is that the location of the solidifying molten metal / liquid molten metal interface is not known and this is determined continuously by appropriate mathematical analysis. This moving interface is normally expressed mathematically by the energy balance equations at the interfaces. In the numerical analysis, as solidification of molten aluminium metal progresses, three boundary interfaces occurred as:

\subsection{Steel mould-atmosphere interface $(I=1)$}

The heat conducted to the steel mould material (from $I=2$ to $1=1$ ) equals the sum of the change in the internal energy and heat convected from the surface of the steel metal mould material into the atmosphere, mathematically represented in equation (26).

$$
\frac{\partial T_{s t}}{\partial t}=\frac{2 K_{s t}}{\rho_{s t} C_{s t} d_{s t}} \frac{\partial T_{s t}}{\partial r}-\frac{2 H^{*}}{\rho_{s t} C_{s t} d_{s t}}\left(T_{i}^{j}-T_{\infty}\right)
$$

$\mathrm{I}=1$

\subsection{In the solidified molten metal-steel mould interface $(I=G)$}

The sum of the heat conducted from the solidifying molten metal/steel mould interface and the change (decrease) in the internal energy at the boundary equal the sum of the heat conducted to the steel mould and the change (increase) in the internal energy at the interface. 


$$
K_{S} \frac{\partial T_{S}}{\partial r}+\frac{1}{2} \rho_{S} C_{S} d_{S} \frac{\partial T_{S}}{\partial t}=K_{s t} \frac{\partial T_{s t}}{\partial r}+\frac{1}{2} \rho_{s t} C_{s t} d_{s t} \frac{\partial T_{s t}}{\partial t}
$$

$\mathrm{I}=\mathrm{G}$

\subsection{In the liquid molten metal - Solidified molten metal interface, $(I=M)$}

The sum of the heat conducted from the liquid molten metal and the internal energy generated equal the sum of heat conducted to the solidified molten metal and the internal energy generated at the interface as in equation (28).

$$
K_{L} \frac{\partial T_{L}}{\partial r}-\frac{1}{2} \rho_{L} C_{L} d_{L} \frac{\partial T_{L}}{\partial t}=K_{S} \frac{\partial T_{S}}{\partial r}+\frac{1}{2} \rho_{S} C_{S} d_{S} \frac{\partial T_{S}}{\partial t}
$$

$\mathrm{I}=\mathrm{M}$

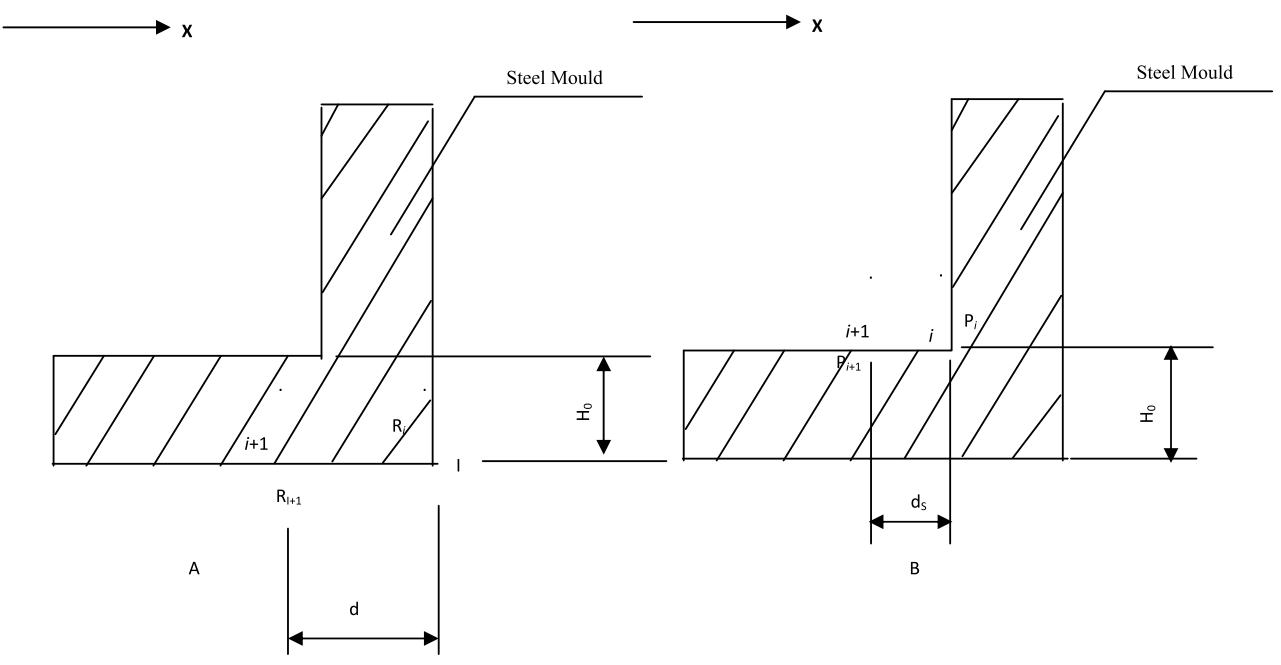

Figure 3. Corner nodes. A) External, B) Internal nodes

\subsection{At the corners}

The usual one dimensional heat transfer analysis does not take into consideration heat loss at the corners as represented in figure 3. Heat loss at both the external and internal corner nodes of the steel mould have been considered and analysed while the die is lagged at the bottom surface.

\subsection{External corner effect}

$$
q_{i+1}+q_{g}=q_{\text {conv }}
$$


The heat conducted from point $\mathrm{R}_{i+1}$ to point $\mathrm{R}_{i}$ added to the change in the internal energy equal the amount of heat convected out to the atmosphere at point R.., Fig. (3a). The finite form of equation (29) is represented by equation (30),

$$
\frac{K_{s t}}{d_{s t}} \frac{\partial T_{s t}}{\partial r}-\frac{1}{2} \rho_{s t} C_{s t} \frac{\partial T_{s t}}{\partial t}=\frac{h}{d_{s t}}\left(T_{i}^{j}-T_{\infty}^{j}\right)+\frac{h}{H}\left(T_{i}^{j}-T_{\infty}^{j}\right)
$$

\subsection{Internal corner effect}

The heat conducted from point $\mathrm{P}_{\mathrm{I}+1}$ to point $\mathrm{P}_{\mathrm{I}}$ added to the change in the internal energy amount to the heat conducted into the steel mould at point I, fig. (3b) thus becoming equation (31);

$$
\frac{K_{S}}{d_{s t}} \frac{\partial T_{S}}{\partial r}+\frac{1}{2} \rho_{S} C_{S} \frac{\partial T_{s t}}{\partial t}=\frac{K_{s t}}{d_{S}} \frac{\partial T_{s t}}{\partial r}+\frac{K_{s t}}{H 1} \frac{\partial T_{s t}}{\partial Z}
$$

\subsection{First time analysis}

Solidification takes place only in the radial direction, a one-dimensional heat solidification problem was assumed numerically to take place in the radial direction only after filling the steel mould cavity with the liquid molten metal.

For the first time analysis, the specimen is considered to be in the molten stage and therefore equation (32) for the liquid molten metal is used for computation. Thus;

$$
\rho_{L} C_{L} \frac{d T_{L}}{d t}=K_{L}\left[\frac{\partial^{2} T_{L}}{\partial r^{2}}+\frac{1}{r_{L}} \frac{\partial T_{L}}{\partial r}\right]
$$

This equation is subjected to the boundary conditions with;

$$
T_{L}=T_{S}
$$

The instantaneous radius $r_{i}$ in the first time analysis is given by equation (34);

$$
r_{L}=\frac{(N-I)}{(N-G)} L
$$

$\mathrm{I}=\mathrm{G}, \mathrm{G}+1, \mathrm{G}+2, \mathrm{G}+3, \ldots ., \mathrm{N}$

The boundary velocity of moving coordinate of equation (32) is given as equation (35);

$$
\frac{d r_{i}}{d t}=\frac{d}{d t}\left[\frac{(N-I)}{(N-G)} L\right]=0
$$




\subsection{At the completion of solidification}

At the completion of solidification, the whole molten region becomes solidified molten metal, and just before pressure is applied, the governing heat transfer equation becomes equation (36) representing the solidified portion;

$$
\rho_{S} C_{S} \frac{\partial T_{L}}{\partial t}=K_{S}\left[\frac{\partial^{2} T_{S}}{\partial r^{2}}+\frac{1}{r_{S C}} \frac{\partial T_{S}}{\partial r}\right]
$$

The equation is applicable within the region defined by equation (37);

$$
r=L
$$

The boundary motion at the completion of solidification is as in equation (38);

$$
r_{S C}=\frac{(N-I)}{(N-G)} L
$$

$\mathrm{I}=\mathrm{G}, \mathrm{G}+1, \mathrm{G}+2, \mathrm{G}+3, \ldots, . \mathrm{N}$

The boundary velocity at the completion of solidification is expressed as equation (39);

$$
\frac{d r_{S C}}{d t}=\frac{d}{d t}\left[\frac{(N-I)}{(N-G)} L\right]=0
$$

where,

L -constant value

\section{Finite difference of governing heat transfer equations}

The heat transfer equations generated in the cast metal and interfaces are written in the finite difference forms. These equations are presented in the various regions thus;

\subsection{In the steel mould region}

$$
T_{i}^{j+1}=\left[1-\frac{2 \delta \alpha_{s t}}{d_{s t}^{2}}-\frac{\delta \alpha_{s t}}{r_{s t} d_{s t}}\right] T_{i}^{j}+\left[\frac{\delta \alpha_{s t}}{d_{s t}^{2}}+\frac{\delta \alpha_{s t}}{r_{s t} d_{s t}}\right] T_{i+1}^{j}+\frac{\delta \alpha_{s t}}{d_{s t}^{2}} T_{i-1}^{j}
$$

where,

$$
\begin{aligned}
& r_{s t}=L+\frac{Q(G-I)}{(G-1)} \\
& d_{s t}=\frac{Q}{(G-I)}
\end{aligned}
$$

$\mathrm{I}=1,2,3, \ldots \ldots \ldots \ldots . \mathrm{G}$ 


\subsection{In the solidified molten metal portion}

$$
\begin{aligned}
& T_{i}^{j+1}=\left[1-\frac{(I-G)}{(M-G)} \frac{\left(X_{r}^{j+1}-X_{r}^{j}\right)}{d_{S}}-\frac{2 \delta \alpha_{S}}{d_{S}^{2}}-\frac{\delta \alpha_{S}}{r_{S} d_{S}}\right] T_{i}^{j}+ \\
& +\left[\frac{(I-G)}{(M-G)} \frac{\left(X_{r}^{j+1}-X_{r}^{j}\right)}{d_{S}}+\frac{\delta \alpha_{S}}{d_{S}^{2}}+\frac{\delta \alpha_{S}}{r_{S} d_{S}}\right] T_{i+1}^{j}+\frac{\delta \alpha_{S}}{d_{S}^{2}} T_{i-1}^{j}
\end{aligned}
$$

where,

$$
\begin{aligned}
& r_{S}=L-\frac{X_{r}^{j}(I-G)}{(M-G)} \\
& d_{S}=\frac{X_{r}^{j}}{(M-I)}
\end{aligned}
$$

$I=G+1, G+2, G+3, \ldots \ldots \ldots, M$

\subsection{In the liquid molten metal region}

$$
\begin{aligned}
& T_{i}^{j+1}=\left[1-\frac{(I-M)}{(N-M)} \frac{\left(X_{r}^{j+1}-X_{r}^{j}\right)}{d_{L}}-\frac{2 \delta \alpha_{L}}{d_{L}^{2}}-\frac{\delta \alpha_{L}}{r_{L} d_{L}}\right] T_{i}^{j}+ \\
& {\left[\frac{(I-M)}{(N-M)} \frac{\left(X_{r}^{j+1}-X_{r}^{j}\right)}{d_{L}}+\frac{\delta \alpha_{L}}{d_{L}^{2}}+\frac{\delta \alpha_{L}}{r_{L} d_{L}}\right] T_{i+1}^{j}+\frac{\delta \alpha_{L}}{d_{L}^{2}} T_{i-1}^{j}}
\end{aligned}
$$

where,

$$
\begin{aligned}
& r_{L}=\left(L-X_{r}^{j}\right) \frac{(I-M)}{(N-M)} \\
& d_{L}=\frac{\left(L-X_{r}^{j}\right)}{(N-I)}
\end{aligned}
$$

$\mathrm{I}=\mathrm{M}, \mathrm{M}+1, \mathrm{M}+2, \mathrm{M}+3, \ldots, \mathrm{N}$

\subsection{In the phase change boundary condition $(I=M)$}

$$
X_{r}^{j+1}=X_{r}^{j}-\left[\frac{\delta K_{L}}{\rho_{L} L_{f} h_{p L}}+\frac{\delta K_{S}}{\rho_{L} L_{f} h_{p s}}\right] T_{i}^{j}+\frac{\delta K_{L}}{\rho_{L} L_{f} h_{p L}} T_{i+1}^{j}+\frac{\delta K_{S}}{\rho_{L} L_{f} h_{p s}} T_{i-1}^{j}
$$


where,

$$
\begin{aligned}
& h_{P L}=\frac{\left(L-X_{r}^{j}\right)}{(N-M)} \\
& h_{P S}=\frac{X_{r}^{j}}{(M-G)}
\end{aligned}
$$

8.5. In the steel mould / atmosphere interface $(I=1)$

$$
T_{i}^{j+1}=\left[1-\frac{2 \delta K_{s t}}{d_{s t}^{2} \rho_{s t} C_{s t}}\right] T_{i}^{j}+\frac{2 \delta K_{s t}}{d_{s t}^{2} \rho_{s t} C_{s t}} T_{i+1}^{j}-\frac{2 \delta H^{*}}{d_{s t} \rho_{s t} C_{s t}}\left(T_{i}^{j}-T_{\infty}^{i}\right)
$$

$\mathrm{I}=1$

where;

$$
d_{s t}=\frac{Q}{(G-1)}
$$

$\mathrm{I}=1,2,3, \ldots, \mathrm{G}$

8.6. In the solidified molten metal / steel mould interface $(I=G)$

$$
\begin{aligned}
& T_{i}^{j+1}=a\left[\frac{2 \delta K_{S}}{d_{S}}+d_{S} \rho_{S} C_{S}+\rho_{S} C_{S} \frac{(I-G)}{(M-G)}\left(X_{r}^{j+1}-X_{r}^{j}\right)+\frac{2 \delta K_{s t}}{d_{s t}}-d_{s t} \rho_{s t} C_{s t}\right] T_{i}^{j} \\
& +a\left[\rho_{S} C_{S} \frac{(I-G)}{(M-G)}\left(X_{r}^{j+1}-X_{r}^{j}\right)-\frac{2 \delta K_{S}}{d_{S}}\right] T_{i+1}^{j}-\frac{2 a \delta K_{s t}}{d_{s t}} T_{i-1}^{j}
\end{aligned}
$$

where,

$$
\begin{gathered}
a=\frac{1}{\left(d_{S} \rho_{S} C_{S}-d_{s t} \rho_{s t} C_{s t}\right)} \\
d_{s t}=\frac{Q}{(G-I)} \\
\mathrm{I}=1,2,3, \ldots, \mathrm{G} \\
d_{S}=\frac{X_{r}^{i}}{(M-I)} \\
\mathrm{I}=\mathrm{G}+1, \mathrm{G}+2, \mathrm{G}+3, \ldots, \mathrm{M}
\end{gathered}
$$


8.7. In the liquid molten metal / solidified molten metal interface $(I=M)$

$$
\begin{aligned}
T_{i}^{j+1}=b\left[\begin{array}{l}
\left.d_{L} \rho_{L} C_{L}-\rho_{L} C_{L} \frac{(I-M)}{(N-M)}\left(X_{r}^{j+1}-X_{r}^{j}\right)-\frac{2 \delta K_{L}}{d_{L}}+d_{S} \rho_{S} C_{S}-\frac{2 \delta K_{S}}{d_{S}}+\right] \\
\rho_{S} C_{S} \frac{(I-G)}{(M-G)}\left(X_{r}^{j+1}-X_{r}^{j}\right)
\end{array}\right] T_{i}^{j} \\
+b\left[\frac{2 \delta K_{S}}{d_{S}}-\rho_{S} C_{S} \frac{(I-G)}{(M-G)}\left(X_{r}^{j+1}-X_{r}^{j}\right)\right] T_{i-1}^{j} \\
+b\left[\frac{2 \delta K_{L}}{d_{L}}+\rho_{L} C_{L} \frac{(I-M)}{(N-M)}\left(X_{r}^{j+1}-X_{r}^{j}\right)\right] T_{i+1}^{j}
\end{aligned}
$$

where,

$$
\begin{aligned}
& b=\frac{1}{\left(d_{S} \rho_{S} C_{S}+d_{L} \rho_{L} C_{L}\right)} \\
& d_{S}=\frac{X_{r}^{j}}{(M-I)} \\
& d_{L}=\frac{\left(L-X_{r}^{j}\right)}{(N-I)}
\end{aligned}
$$

$\mathrm{I}=\mathrm{M}, \mathrm{M}+1, \mathrm{M}+2, \mathrm{M}+3, \ldots, \mathrm{N}$

\subsection{External corner effect $(I=1)$}

$$
\begin{aligned}
T_{i}^{j+1} & =\left[1-\frac{2 \delta K_{s t}}{\rho_{s t} C_{s t} d_{s t}^{2}}-\frac{2 \delta h}{\rho_{s t} C_{s t} d_{s t}}-\frac{2 \delta h}{\rho_{s t} C_{s t} H}\right] T_{i}^{j}+ \\
& +\frac{2 \delta K_{s t}}{\rho_{s t} C_{s t} d_{s t}^{2}} T_{i+1}^{j}+ \\
& +\left[\frac{2 \delta h}{\rho_{s t} C_{s t} d_{s t}}+\frac{2 \delta h}{\rho_{s t} C_{s t} H}\right] T_{\infty}^{j}
\end{aligned}
$$

where,

$$
d_{s t}=\frac{Q}{(G-I)}
$$




\subsection{Internal corner effect $(I=G)$}

$$
\begin{aligned}
& T_{i}^{j+1}=\left[1+\frac{2 \delta K_{S}}{\rho_{S} C_{S} d_{S}^{2}}+\frac{(I-G)}{(M-G)} \frac{\left(X_{r}^{j+1}-X_{r}^{j}\right)}{d_{S}}+\frac{2 \delta K_{s t}}{\rho_{S} C_{S} d_{S} d_{s t}}+\frac{2 \delta K_{s t}}{\rho_{S} C_{S} H 1 d_{s t}}\right] T_{i}^{j}- \\
& -\frac{2 \delta K_{S}}{\rho_{S} C_{S} d_{S}^{2}} T_{i+1}^{j}-\left[\frac{2 \delta K_{s t}}{\rho_{S} C_{S} d_{S} d_{s t}}+\frac{2 \delta K_{s t}}{\rho_{S} C_{S} H 1 d_{s t}}\right] T_{i-1}^{j}
\end{aligned}
$$

where,

$$
\begin{gathered}
d_{S}=\frac{X_{r}^{j}}{(M-I)} \\
\mathrm{I}=\mathrm{G}+1, \mathrm{G}+2, \mathrm{G}+3, \ldots, \mathrm{M} \\
d_{s t}=\frac{Q}{(G-I)} \\
\mathrm{I}=1,2,3, \ldots, \mathrm{G}
\end{gathered}
$$

\subsection{First time analysis}

Finite difference form of equation (32) therefore becomes equation (58);

$$
T_{i}^{j+1}=\left[1-\frac{2 \delta \alpha_{L}}{d_{L}^{2}}-\frac{\delta \alpha_{L}}{r_{L} d_{L}}\right] T_{i}^{j}+\left[\frac{\delta \alpha_{L}}{d_{L}^{2}}+\frac{\delta \alpha_{L}}{r_{L} d_{L}}\right] T_{i+1}^{j}+\frac{\delta \alpha_{L}}{d_{L}^{2}} T_{i-1}^{j}
$$

where,

$$
\begin{aligned}
& r_{L}=\frac{(N-I)}{(N-G)} L \\
& d_{L}=\frac{L}{(N-G)}
\end{aligned}
$$

$\mathrm{I}=\mathrm{G}+1, \mathrm{G}+2, \mathrm{G}+3, \ldots \ldots \ldots, . \mathrm{N}$

\subsection{At the completion of solidification}

Finite difference form of equation (36) becomes equation (60);

$$
T_{i}^{j+1}=\left[1-\frac{2 \delta \alpha_{S}}{d_{S C}^{2}}-\frac{\delta \alpha_{S}}{r_{S C} d_{S C}}\right] T_{i}^{j}+\left[\frac{\delta \alpha_{S}}{d_{S C}^{2}}+\frac{\delta \alpha_{S}}{r_{S C} d_{S C}}\right] T_{i+1}^{j}+\frac{\delta \alpha_{S}}{d_{S C}^{2}} T_{i-1}^{j}
$$

where; 


$$
\begin{aligned}
& r_{S C}=\frac{(N-I)}{(N-G)} L \\
& d_{S C}=\frac{L}{(N-G)}
\end{aligned}
$$

$\mathrm{I}=\mathrm{G}+1, \mathrm{G}+2, \mathrm{G}+3, \ldots,(\mathrm{N}-1)$

\section{Stability criteria}

For stability criteria to be achieved, the values of temperature $T_{i}^{j}$ in all the heat governing equations should not be negative according to Ozisik (1985) and White (1991) not to negate the law of thermodynamics which could lead to temperature fluctuations. Therefore, for stability to be achieved, the coefficients of $T_{i}^{j}$ in each of the equations must be greater than zero.

\section{Casting with pressure application and die heating}

Pressure was applied only when the cast specimen was solidified, the governing heat transfer equation therefore, takes the form of solidified molten metal (completion of solidification). The finite difference of equation (8) is written as equation (62);

$$
T_{i}^{j+1}=\left[1-\frac{2 \delta \alpha_{S}}{d_{S}^{2}}-\frac{\delta \alpha_{S}}{r_{S} d_{S}}\right] T_{i}^{j}+\left[\frac{\delta \alpha_{S}}{d_{S}^{2}}+\frac{\delta \alpha_{S}}{r_{S} d_{S}}\right] T_{i}^{j}+\frac{\delta \alpha_{S}}{d_{S}^{2}} T_{i-1}^{j}+\Delta T
$$

where,

$\Delta \mathrm{T}$-temperature change resulting from pressure application

The cast specimen height, $h_{c}$, is pressure dependent and the relationship is expressed with the equation (63) below after performing series of experiment with various applied pressure;

$$
h_{c}=-0.00007 P+0.036833
$$

where coefficient of correlation $r=0.996$

The plastic flow stress, $\sigma_{(\mathrm{T})}$, is dependent on both the applied pressure, $\mathrm{P}$, and die temperature, TM, (White, 1991), and expressed with the equation (64);

$$
\sigma(T)=0.244 P-0.0405 T M+18.614
$$

where coefficient of correlation $r=0.9508$

\section{Casting with die heating}

Aluminium cast specimens were produced with die pre- heating temperatures of between $100-300^{\circ} \mathrm{C}$ without applying pressure on the solidifying aluminium metal. The die heating 
process was carried out, using three electric heater rods (100Watts each) that were connected to a.c supply. The required die temperatures were set and controlled, using a bimetallic thermostat.

\section{Heat transfer coefficient evaluations}

The method of calculating heat transfer coefficients as reported by Santos et al (2001) and Maleki et al, (2006) is based on the knowledge of known temperature histories at the interior points of the casting or mould together with the numerical models of heat flow during solidification. These temperatures are difficult to measure due to the difficulty in locating accurate position of thermocouple at the interface. Therefore, the inverse heat conduction problem based on non-linear estimation technique of Chattopadhyay, (2007) and $\mathrm{Hu}$ and $\mathrm{Yu}$, (2002), has been adopted to determine the values of interface heat transfer coefficients, as a function of time during solidification of squeeze casting. Solidification of squeeze casting of aluminium involves phase change and therefore thermal properties of aluminium are temperature dependent, making the inverse heat conduction problem non-linear.

The governing heat transfer equation in one-dimensional cylindrical coordinates is given by equation (65):

$$
\rho c_{p} \frac{\partial T}{\partial t}=\frac{1}{r} \frac{\partial}{\partial r}\left(K_{a l} r \frac{\partial T}{\partial r}\right)
$$

Equation (65) holds within the boundary condition as expressed in equation (66):

$$
q=K_{a l}(T) \frac{\partial T}{\partial r}=h_{a l}(T)\left[T_{a l}-T_{M}\right]
$$

The thermal conductivity Kal (Reed-Hill and Abbaschian 1973) and (Elliot, 1988) of aluminium is dependent upon casting temperature, $\mathrm{T}_{\mathrm{al}}$, and expressed in equation (67):

$$
K_{a l}(T)=241.84-0.041 T_{a l}
$$

The heat flow across the casting/mould interface can be characterized by an average interfacial heat transfer coefficient, hal $(\mathrm{T})$ as obtained by Gafur et al (2003) and Santos et al (2004). This is expressed mathematically in equation (68):

$$
h_{a l}(T)=\frac{q}{\left[T_{a l}-T_{M}\right]}
$$

The heat transfer coefficient, $h$, at the interface is estimated by minimizing the errors between numerically estimated and measured temperatures defined by equation (69):

$$
F(h)=\sum_{i=1}^{n}\left(T_{\text {est }}-T_{\text {exp }}\right)^{2}
$$


where,

Test and Texp -are the estimated and experimentally measured temperatures at various thermocouples location and times,

$\mathrm{n}$-iteration stage

\section{Numerical simulations of differential equations}

Squeeze casting consists of two stages, the first of which is mould filling: - the mould is filled with the required quantity of liquid molten metal; the second is cooling, this continues until the part has solidified completely. Controlling both stages is of major importance for obtaining sound casts with the required geometry and mechanical properties as observed by (Kobryn and Semiatin, (2000), Browne and O'Mahoney, (2001) and Martorano and Capocchi, (2000). When molten metal is poured into the mould cavity, it is initially in the liquid state with a high fluidity. It quickly becomes very viscous, in the early stage of solidification, and later completely solidifies (Gafur et al, 2003). For the numerical analysis of heat transfer problem, the appropriate set of equations were determined that described the heat transfer behaviour in the cast metal (Hearn, 1992). With the boundary conditions, initial conditions, and thermo-physical properties of the materials being known, it is possible to obtain the temperature and variation of the whole casting system (Ozisik, 1985) and (Liu et al (1993). Finite number at discrete points (Adams and Rogers, (1973), Shampire, (1994) and Bayazitoglu and Ozisik, (1988)) within the cast specimen was employed as the numerical method of solution. This method provides the temperature at a discrete number of points in the cast region. In the numerical method, the cast region is defined and divided into discrete number of points. As temperature difference is imposed in the system, heat flows from the high-temperature region to the low-temperature region as shown in figure 1.

To determine the temperature distribution, energy conservation equations were used for each of the nodal points of the unknown temperature at the interfaces and the cast regions ((Incropera and Dewitt, 1985) and (Janna, 1988)). Temperatures were monitored at distance $2 \mathrm{~mm}$ into the cast metal, represented by grid point $\mathrm{M}$, and at the steel mould/cast metal interface (see figure 4). By using measured temperatures in both the casting and the steel mould, together with the numerical solutions of the solidification problem, heat transfer coefficients were determined based on Beck (1970) solution of the inverse heat conduction problem. The estimation of the surface heat transfer coefficients or heat flux density utilizing a measured temperature history inside a heat-conducting solid is called the inverse heat conduction problem (Cho and Hong 1996). This problem becomes non-linear, as the thermal properties (thermal conductivity, specific heat) are temperature dependent.

\section{Experimental procedure}

Chromel-Alumel thermocouples TC2, TC3, TC4, TC5 and TC6 were positioned on the sides of the cylindrical steel container, while TC1 and TC7 were positioned in the cast aluminium metal in the cylindrical and bottom flat surfaces respectively as shown in figure 4 below. 
Thermocouples of chromel-alumel type, $3 \mathrm{~mm}$ in diameter were used to determine the solidifying temperatures of the cast molten metal and heating temperatures of the steel mould at the various positions in the cylindrical steel container of figure 4 . The solidifying temperatures at both the cylindrical and flat bottom surfaces of the cast molten aluminium metal were monitored at a position $2 \mathrm{~mm}$ (from the surface of the steel mould -cast aluminium metal interface) into the cast molten aluminium metal.

At the steel mould wall in the cylindrical surface, thermocouples were positioned at $\mathrm{X} 2=$ $4 \mathrm{~mm}, \mathrm{X} 3=8 \mathrm{~mm}, \mathrm{X} 4=12 \mathrm{~mm}, \mathrm{X} 5=16 \mathrm{~mm}$ and $\mathrm{X} 6=20 \mathrm{~mm}$ measured from the cast aluminium metal / steel mould interface to monitor the heating temperatures at these positions of the steel mould wall as shown in fig. 4. From the temperatures versus time curves obtained for each position in the steel mould, the interface heating temperature versus time curve at the cast aluminium metal / steel mould, for position when $\mathrm{X}=0$ was obtained by using the polynomial curve fitting method.

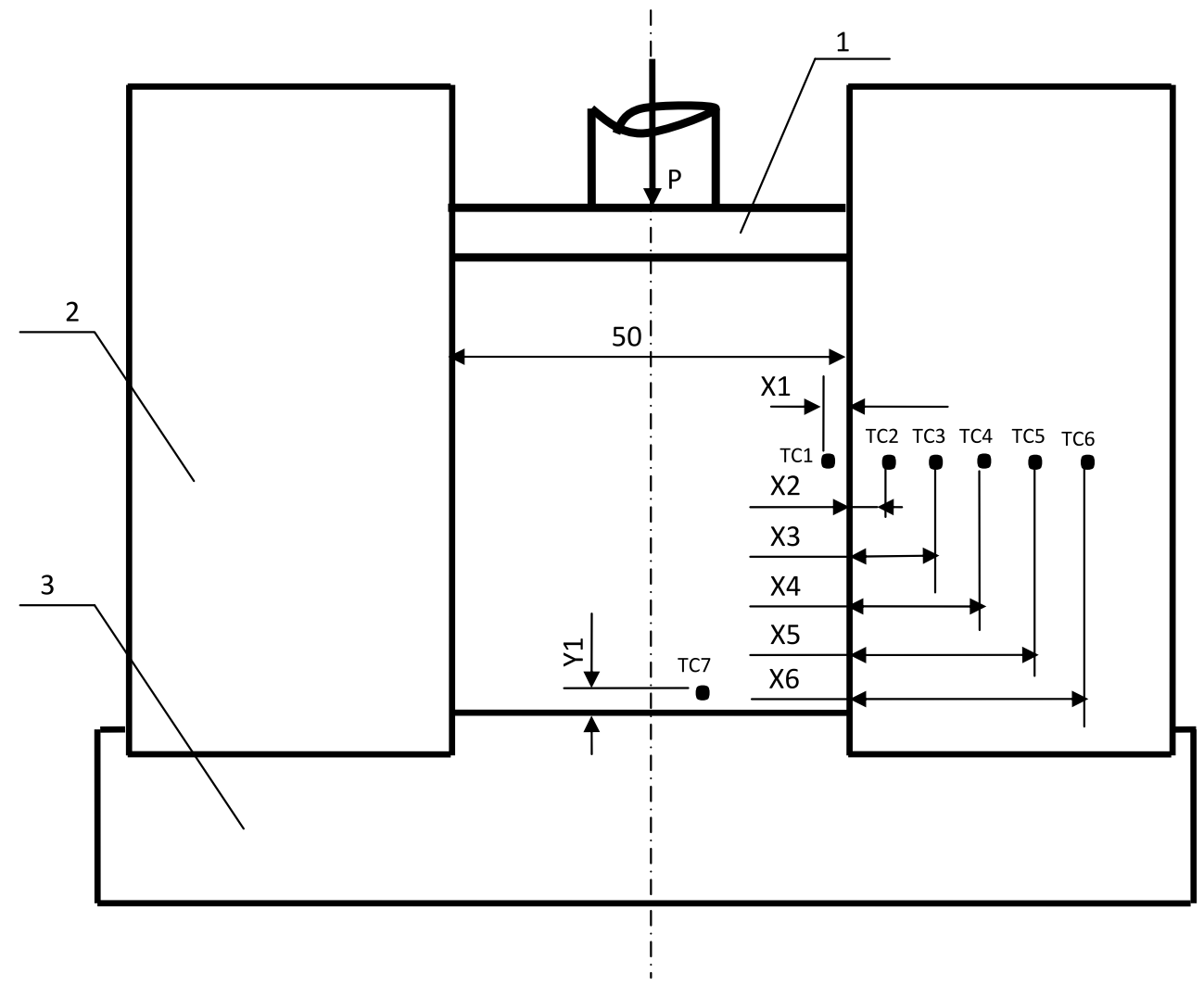

1-upper punch, 2-cylindrical steel mould, 3-lower die $(X 1=2, X 2=4, X 3=8, X 4=12, X 5=16, X 6=20, Y 1=2(\mathrm{~mm}))$

Figure 4. Schematic diagram of squeeze casting test rig 
This was done by selecting a particular time of heating of steel mould, say $t=10$ sec. and drawing vertical lines cutting across the heating temperatures versus time curves at various thermocouples' distances within the steel mould. At the point of intersection with each curve, the value of temperature was read against distance $X$, for the chosen time, $t=10$ sec. The value of interface steel mould / cast temperature at time say, $t=10 \mathrm{sec}$. was determined at the steel mould / cast metal interface by substituting the value of $X=0$ in the polynomial curve fitting equation (70) obtained from the values of temperatures at various distances in the steel mould at a chosen time, $t=10$ sec.

$$
T_{X 0}=0.0031 X^{4}-0.168 X^{3}+3.263 X^{2}-22.812 X+117.8
$$

The temperature obtained by this method corresponds to the interface steel mould / cast metal temperature at a distance $X=0$ for the chosen time $t=10$ sec. If this procedure is repeated for a number of time increments, the temperatures obtained with corresponding times represent the temperature at $X=0$, for such time increments. The graph of extrapolated temperatures versus time is drawn for position when $X=0$ to represent the heating temperatures versus time curve at the steel mould / cast aluminium metal interface is shown in figure 5.

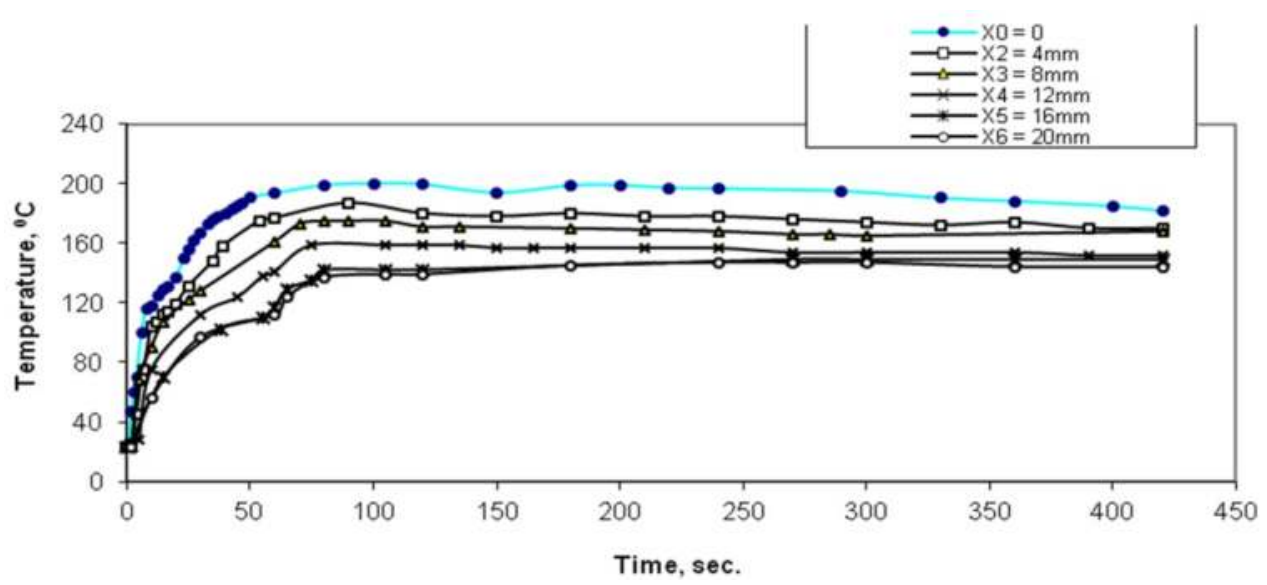

Figure 5. Effect of distance on the heating temperatures of steel mould (extrapolated heating curve at the cast specimen/steel mould interface i.e. $X=0$ )

\section{Interface heat transfer coefficients determination}

Extrapolated temperature versus time curve of figure 5 for position when $X=0$ (i.e. cast aluminium metal / steel mould interface) was used to determine the heat transfer coefficients of solidifying molten aluminium metal. It was used to determine the interface heat transfer coefficients in the cast aluminium metal / steel mould for no pressure and with pressure applications at both the cylindrical and bottom flat surfaces of the steel mould. 
The interface heat transfer coefficients between the steel mould and cast aluminium metal at the cylindrical and bottom flat surfaces were determined from the extrapolated experimental heating temperature versus time curve obtained for position $X=0$ and aluminium cast solidification temperature versus time curves obtained for the cylindrical and bottom flat surfaces, using equations (66) and (67).

The interface heat transfer coefficients were determined also numerically by the inverse method using the Finite Difference Method (FDM) and the obtained results were compared with the experimentally derived values.

\section{Discussions of results}

\subsection{Temperature-time curves}

Figure 6 shows typical temperature versus time curves for solidifying molten aluminium metal and steel mould respectively without the application of pressure on solidifying metal.

This figure shows the comparison of the numerical method usually applied by Cho and Hong (1996) to determine interface steel mould / cast metal temperature versus time curve with the extrapolated experimental method of this present work. The heating curve, as obtained through extrapolations of polynomial curves fitting equations and numerical methods are in close agreement and the deviations from the values obtained numerically varied from between 1.26- 19.31\%.

Typical result obtained under pressure is also shown in figure 7 , indicating the solidification and heating curves generated for solidifying molten aluminium metal and steel mould which follow the same patterns to the curves in figure 6 .

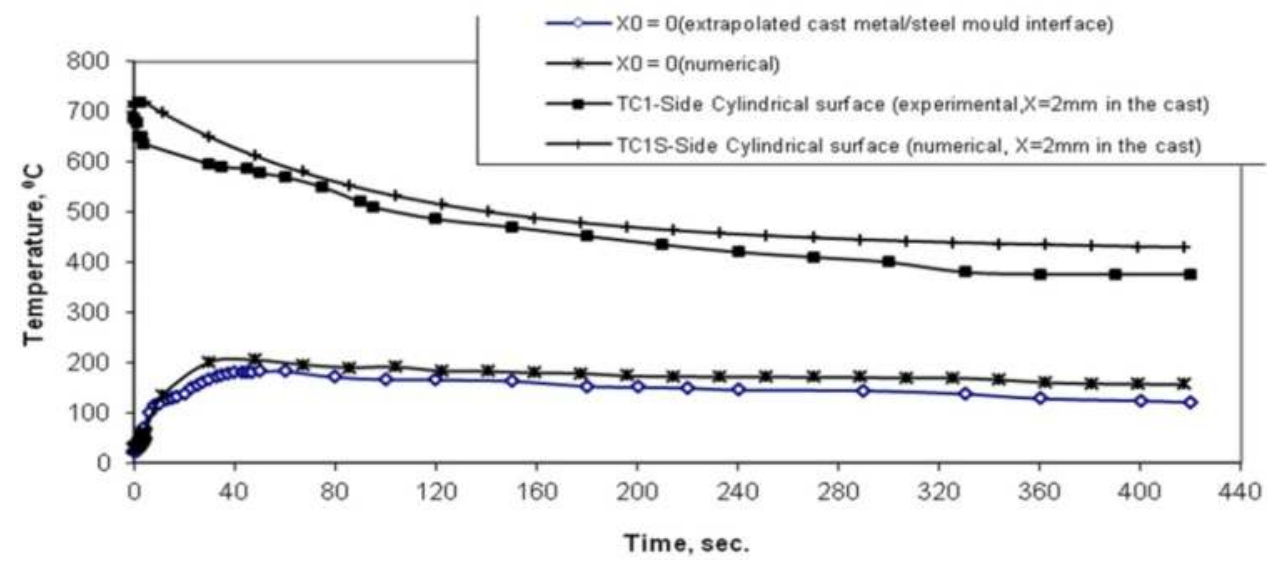

Figure 6. Comparison of experimental measured temperatures with numerical values of aluminium metal without pressure application $(\mathrm{P}=0)$

With the application of pressure, the peak temperatures recorded are about the same $649^{\circ} \mathrm{C}$ and $648^{\circ} \mathrm{C}$ for a pressure of $85.86 \mathrm{MPa}$ at the bottom flat and cylindrical surfaces of the steel 
mould respectively (see figure 7 ). The peak temperature $\left(649^{\circ} \mathrm{C}\right)$ obtained at the bottom flat surface of the steel mould under applied pressure is found to be higher than that temperature $\left(607^{\circ} \mathrm{C}\right)$ without pressure application. This effect may be associated to additional internal heat generated, resulting to higher temperature during pressure application on the solidifying molten aluminium.

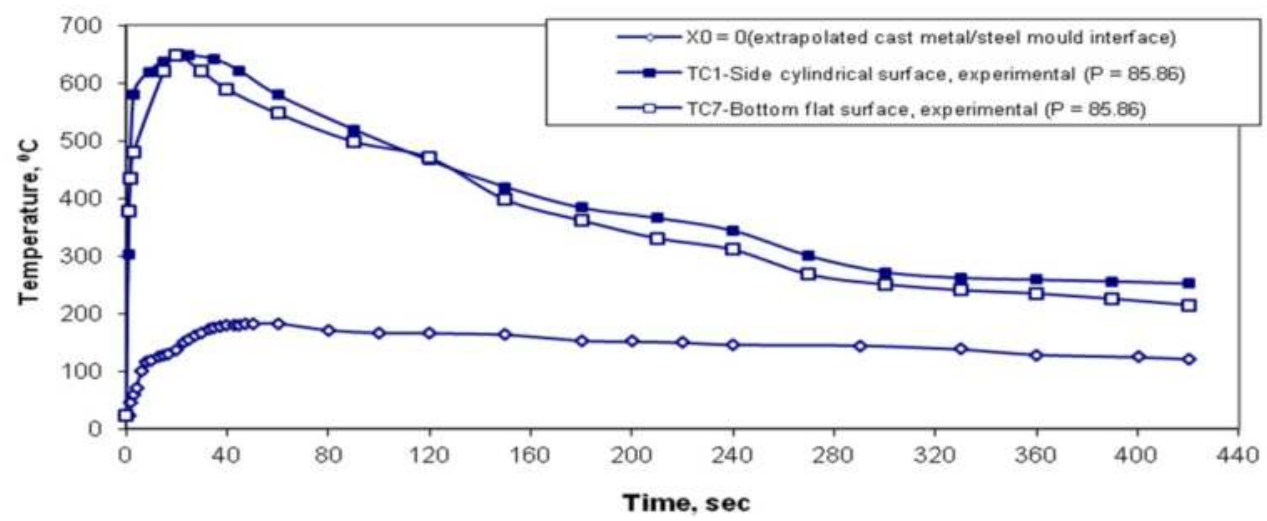

Figure 7. Effect of pressure on the experimental measured temperatures of solidification of aluminium metal $(\mathrm{P}=85.86 \mathrm{MPa})$ for side and bottom mould's surface

\subsection{Interface heat transfer coefficients with time}

From the temperature with time curves of figure 6, the heat transfer coefficients for both cylindrical and bottom flat surfaces were determined for both numerical and calculated values and shown in figure 8 . The maximum heat transfer coefficients of $2927.92 \mathrm{~W} / \mathrm{m}^{2} \mathrm{~K}$ and $2975.14 \mathrm{~W} / \mathrm{m}^{2} \mathrm{~K}$ are obtained at the cylindrical and bottom flat surfaces respectively for no pressure application, which is close to $2900 \mathrm{~W} / \mathrm{m}^{2} \mathrm{~K}$ as obtained for pure aluminium by Kim and Lee (1997). The values of heat transfer coefficients decrease rapidly for both the cylindrical and bottom flat surfaces to a level of $866.70 \mathrm{~W} / \mathrm{m}^{2} \mathrm{~K}$ and $969.50 \mathrm{~W} / \mathrm{m}^{2} \mathrm{~K}$ respectively in 90 seconds. These values further decrease to $361.80 \mathrm{~W} / \mathrm{m}^{2} \mathrm{~K}$ and 478.80 $\mathrm{W} / \mathrm{m}^{2} \mathrm{~K}$ at these surfaces in another 150 seconds and further decrease then becomes not so noticeable.

From figure 8 , the peak values of interface heat transfer coefficients are $2927.92 \mathrm{~W} / \mathrm{m}^{2} \mathrm{~K}$ and $2956.73 \mathrm{~W} / \mathrm{m}^{2} \mathrm{~K}$ as obtained by experimental and numerical determinations respectively at the cylindrical surface for no pressure application. For times within 40 seconds to 120 seconds the values of the interfacial heat transfer coefficients obtained numerically and experimentally are found to show higher values of about $19.83 \%$ for numerical results to experimental results.

With the application of pressure on the solidifying aluminium metal, the heat transfer coefficients reach maximum values of $3085.34 \mathrm{~W} / \mathrm{m}^{2} \mathrm{~K}$ and $3351.08 \mathrm{~W} / \mathrm{m}^{2} \mathrm{~K}$ in the cylindrical and bottom flat surfaces respectively (see figure 9). These values also decrease to 847.80 
$\mathrm{W} / \mathrm{m}^{2} \mathrm{~K}$ and $783.63 \mathrm{~W} / \mathrm{m}^{2} \mathrm{~K}$ in 240 seconds in the cylindrical and bottom flat surfaces respectively, while further decrease with time of solidification is no longer pronounced.

\subsection{Interface heat transfer coefficients with solidification temperatures}

Figures 10 and 12 show the calculated experimental interface heat transfer coefficients for solidifying molten aluminium metal as a function of solidification temperatures of the solidifying molten aluminium metal. Figure 10 shows the variation of heat transfer coefficient with solidification temperatures of aluminium at the cylindrical surface, while figure 12 is the interface heat transfer coefficients with solidifying temperature at the bottom flat surface with and without the application of pressure on the solidifying metal. From the two graphs, the maximum interface heat transfer coefficients obtained without pressure and with pressure application in the bottom flat surface of the steel mould are $2975.14 \mathrm{~W} / \mathrm{m}^{2} \mathrm{~K}$ and $3351.08 \mathrm{~W} / \mathrm{m}^{2} \mathrm{~K}$ respectively.

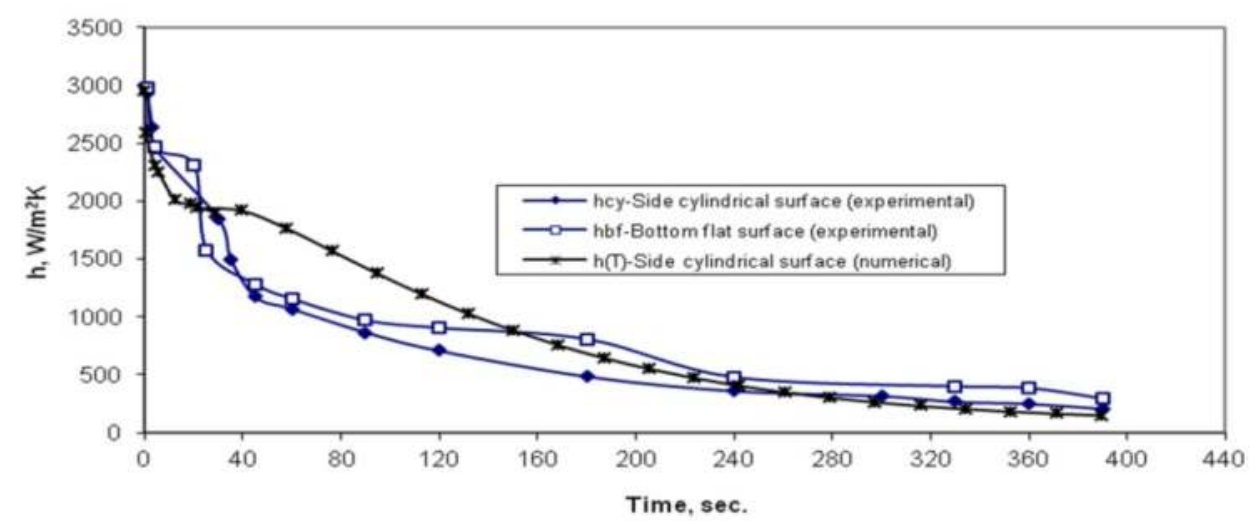

Figure 8. Comparison of numerical values of heat transfer coefficients with calculated experimental values $(\mathrm{P}=0)$

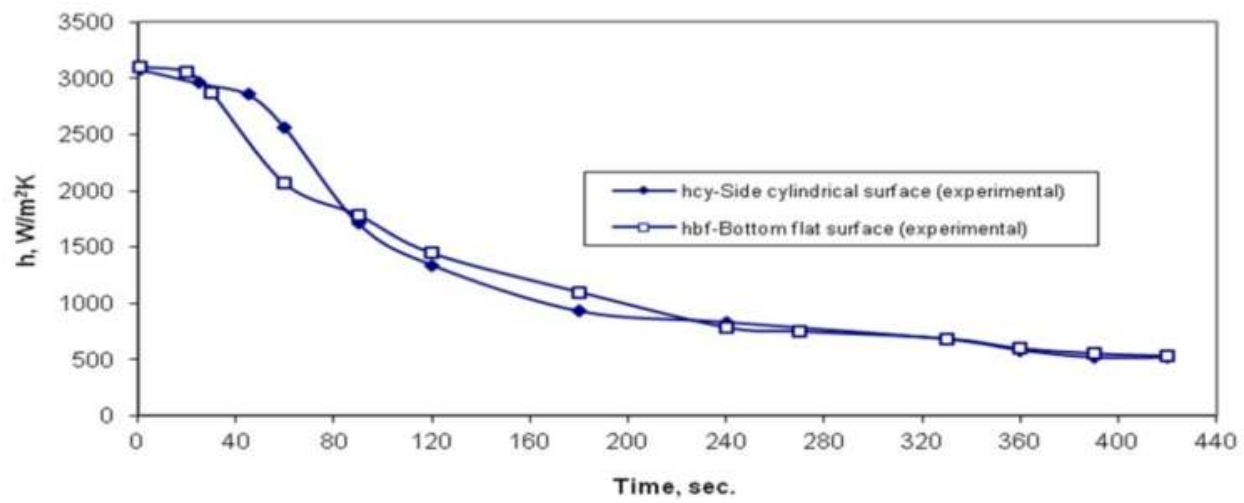

Figure 9. Effect of time of solidification of aluminium metal on heat transfer coefficients with pressure application $(\mathrm{P}=85.86 \mathrm{MPa})$ at side and bottom surfaces of steel mould 
Figure 11 shows the numerical values of the variation of interface heat transfer coefficients with the solidification temperature of aluminium metal at the cylindrical surface with the application of pressure. The maximum value of heat transfer coefficient of $3397.29 \mathrm{~W} / \mathrm{m}^{2} \mathrm{~K}$ at applied pressure of $85.86 \mathrm{Mpa}$ as compared to $3351.08 \mathrm{~W} / \mathrm{m}^{2} \mathrm{~K}$ obtained through the experimental procedure.

At solidifying temperature above $600^{\circ} \mathrm{C}$, a sharp reduction in the interface heat transfer coefficients is noticed at both surfaces as is shown on figures 10, 11 and 12.

For temperatures below $500^{\circ} \mathrm{C}$, the interface heat transfer coefficients for both no pressure and pressure applications are close in values. This shows that at temperature below $500^{\circ} \mathrm{C}$, the effect of applied pressure is no longer significant on the interface heat transfer coefficient values. The drop in temperature results in solidification of the molten aluminium, which in turn leads to a drop in the heat transfer coefficient values. The effect of applied pressure on the heat transfer coefficients of aluminium becomes more pronounced at solidifying temperatures above $500^{\circ} \mathrm{C}$ which was also reported by Cho and Hong (1996). Below this temperature, the effect of applied pressure on interface heat transfer coefficient values becomes less pronounced.

Therefore, from figures 10, 11 and 12, it is observed that the effect of applied pressure becomes more significant at temperature close to the liquidus temperature of aluminium as measured along the bottom flat surface of the steel mould (see figure 12). The maximum value of $3397.29 \mathrm{~W} / \mathrm{m}^{2} \mathrm{~K}$ is obtained for pressure level of $85.86 \mathrm{MPa}$ as compared to 2975.14 $\mathrm{W} / \mathrm{m}^{2} \mathrm{~K}$ for no pressure at the bottom flat surface of the steel mould.

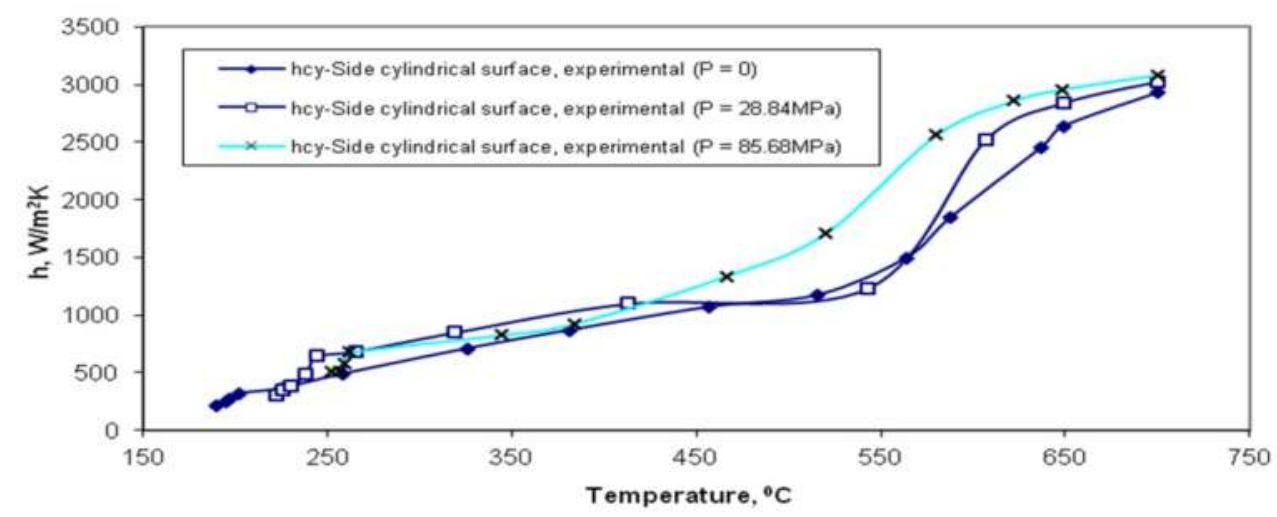

Figure 10. Typical effects of pressure applications on heat transfer coefficients with solidifying temperature at the side cylindrical mould surface by experimental method

\subsection{Peak interface heat transfer coefficients with applied pressures}

Figure 13 shows the variation of peak values of interface heat transfer coefficients with and without pressure applications. Higher experimental values of heat transfer coefficients are obtained at the bottom flat surface than at the cylindrical surface of the steel mould (see 
figure 13). This can be associated to greater effect of pressure application experienced at the bottom flat surface than at the side cylindrical surface, thus leading possibly to greater additional internal heat energy generated, and hence obtained higher values of heat transfer coefficients. The results of numerical determination of heat transfer coefficients as in figure 13 shows higher values as compared to the values obtained by experimental method. At applied pressure of $85.86 \mathrm{MPa}$, the obtained heat transfer coefficients are $3397.29 \mathrm{~W} / \mathrm{m}^{2} \mathrm{~K}$ and $3351.08 \mathrm{~W} / \mathrm{m}^{2} \mathrm{~K}$ by numerical and experimental procedures respectively. From the curves of heat transfer coefficients obtained with temperatures of figures 10, 11 and 12, three distinct portions are noticed. These portions are easily differentiated by the aluminium solidification temperature. These temperatures are below $500^{\circ} \mathrm{C}$, solidus phase, 500 to $660^{\circ} \mathrm{C}$, liquidussolidus phase, and above $660^{\circ} \mathrm{C}$ liquidus phase of solidification of molten aluminium.

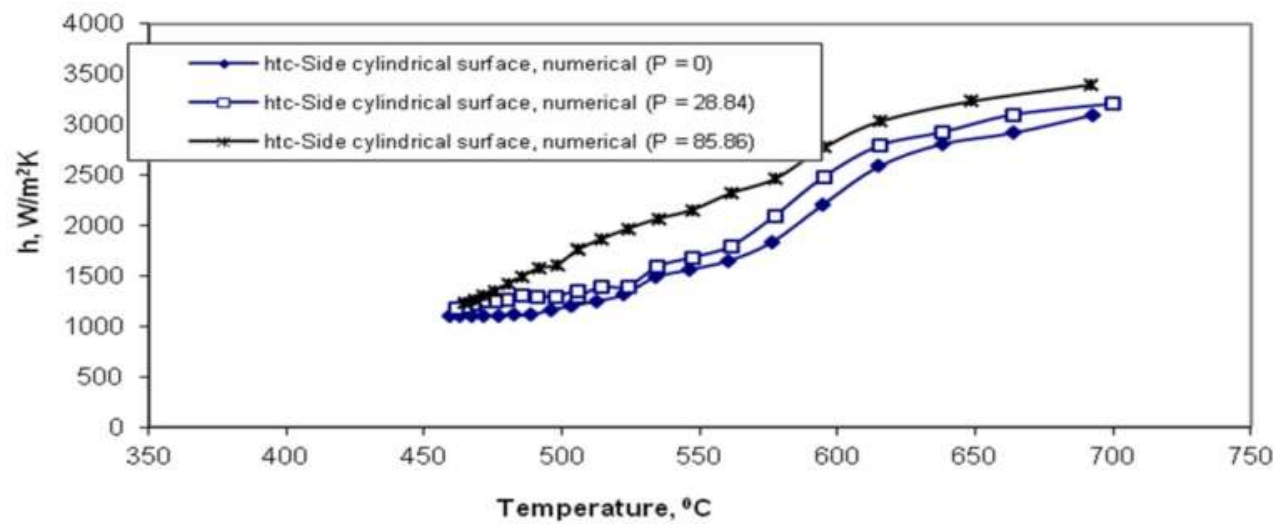

Figure 11. Typical effects of pressure application on heat transfer coefficients with solidifying temperature of the side cylindrical mould surface by numerical method

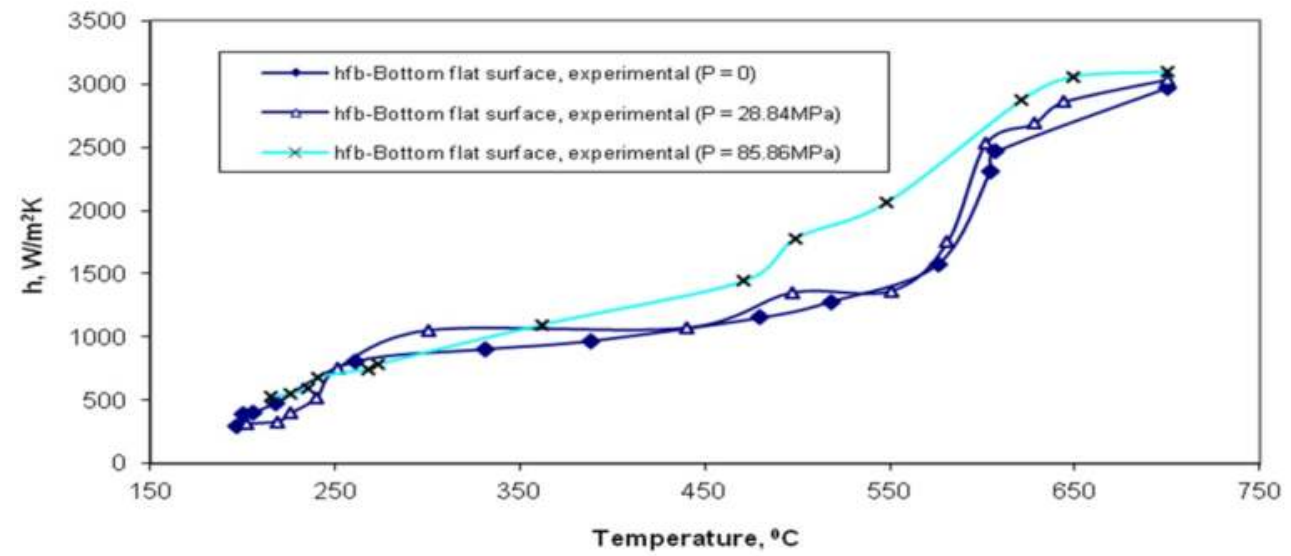

Figure 12. Typical effects of pressure applications on the heat transfer coefficients with solidifying temperature at the bottom flat mould surface 
The liquidus-solidus phase, which occurs over a solidification temperature range of $500^{\circ} \mathrm{C}$ to $660^{\circ} \mathrm{C}$, instead of a constant solidification temperature of $660^{\circ} \mathrm{C}$ can be attributed to the presence of impurities such as silicon, magnesium and manganese in the commercially pure aluminium a fact supported by Higgins (1983).

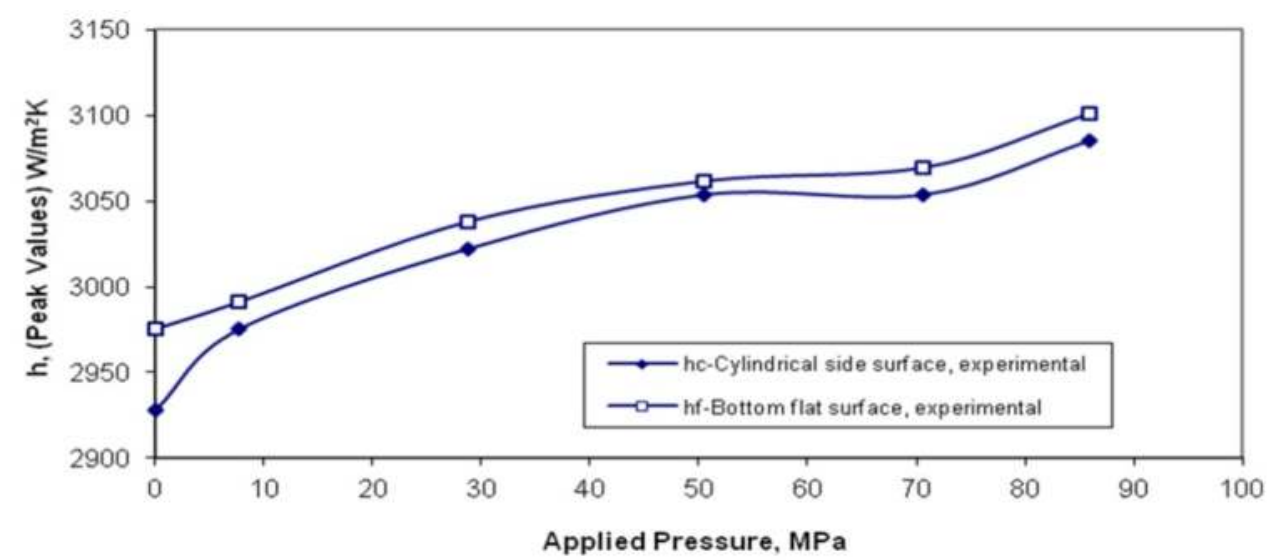

Figure 13. Effect of pressure on the peak values of heat transfer coefficients of aluminium metal at liquidus stage at side and bottom flat moulds' surfaces

The empirical equations for each of the distinct phase changes as a function of applied pressures and solidification temperatures are determined for both the experimental and numerical methods. The empirical equations obtained are for mean average values of heat transfer coefficients based on the experimental method at the cylindrical and flat bottom surfaces. These are equations (71-73):

Temperatures below $500^{\circ} \mathrm{C}$ (solidus phase),

$$
h_{S(\exp )}=3.081 T+1.303 P-232.942
$$

with coefficient of correlation $r=0.9545$.

Temperatures between $500^{\circ} \mathrm{C}$ and $660^{\circ} \mathrm{C}$ (liquidus-solidus phase),

$$
h_{L S(\exp )}=10.420 T+5.641 P-4176.022
$$

with coefficient of correlation $r=0.9884$.

Temperatures above $660^{\circ} \mathrm{C}$ (super heat, liquidus phase),

$$
h_{L(\exp )}=2.769 T+2.518 P+988.921
$$

with coefficient of correlation $r=0.7825$.

The empirical equations (74-76) obtained through the numerical methods are from the results of the computer simulations of heat transfer coefficients at the cylindrical cast metal / 
steel mould interface by the application of various applied pressures. These empirical equations are:

Temperatures below $500^{\circ} \mathrm{C}$ (solidus phase),

$$
h_{S(\text { nит })}=3.849 T+3.643 P-700.427
$$

with coefficient of correlation $\mathrm{r}=0.969$

Temperatures between $500^{\circ} \mathrm{C}$ and $660^{\circ} \mathrm{C}$ (liquidus-solidus phase),

$$
h_{L S(\text { пит })}=9.027 T+3.414 P-3000.625
$$

with coefficient of correlation $r=0.964$

Temperatures above $660^{\circ} \mathrm{C}$ (super heat, liquidus phase),

$$
h_{L(\text { num })}=2.489 T+2.787 P+1342.19
$$

with coefficient of correlation $\mathrm{r}=0.772$

\subsection{Die heating effect}

Figure 14 is the effect of die pre-heat temperatures on the values of heat transfer coefficients of aluminium metal without the application of pressure. From the figure, the heat transfer coefficients become lower with increase in die pre-heat temperatures. At die temperature of $95^{\circ} \mathrm{C}$, the heat transfer coefficient is $3185.34 \mathrm{~W} / \mathrm{m}^{2} \mathrm{~K}$ and drop to a value of $2476.73 \mathrm{~W} / \mathrm{m}^{2} \mathrm{~K}$ at die temperature of $300^{\circ} \mathrm{C}$. For all the die temperatures, there is a fall in the heat transfer coefficient's values as solidification temperature decreases.

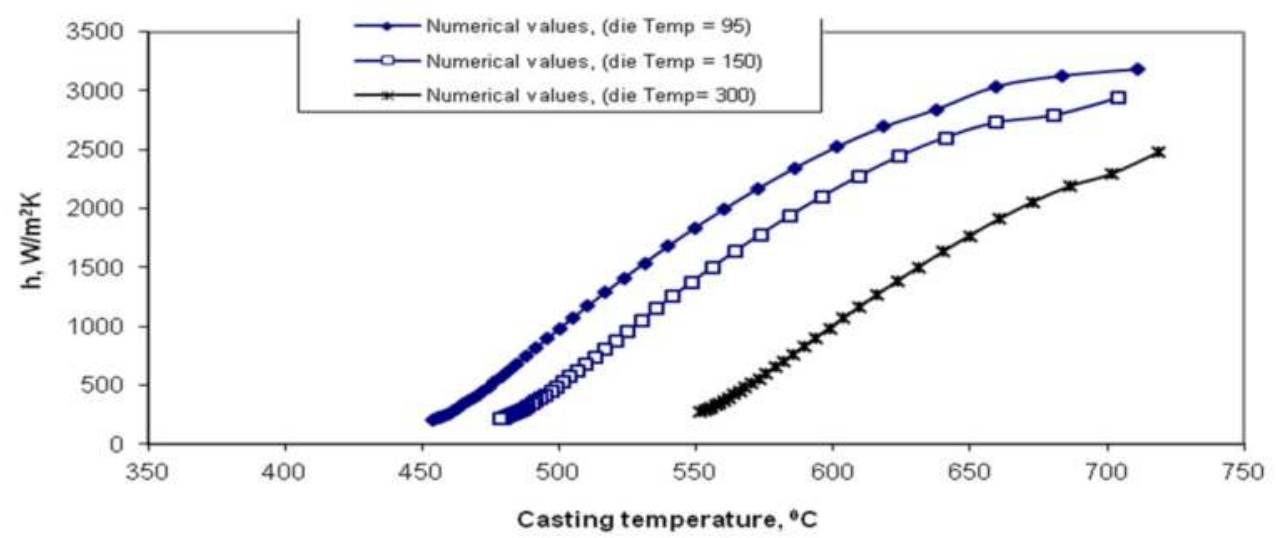

Figure 14. Typical effect of die temperature on heat transfer coefficients without the application of pressure $(\mathrm{P}=0)$ 


\subsection{Comparison of heat transfer coefficient with semi-empirical method}

The values of heat transfer coefficients determined using experimental, heat differential equations (numerical), and methods of semi-empirical equations are shown in figure 15 under a pressure application of $85.86 \mathrm{MPa}$. From this graph, the peak values of interface heat transfer coefficient are $3358.19 \mathrm{~W} / \mathrm{m}^{2} \mathrm{~K}$ and $3198.79 \mathrm{~W} / \mathrm{m}^{2} \mathrm{~K}$ as obtained by heat differential and method of semi-empirical equations respectively for a pressure application of $85.86 \mathrm{MPa}$. The heat transfer coefficients' values for the three methods drop with time and are found to be $1708.03,1976.81$ and $1838.72 \mathrm{~W} / \mathrm{m}^{2} \mathrm{~K}$ in 100 seconds for experimental, differential and methods of semi-empirical equations respectively.

With die temperature of $\mathrm{TM}=150^{\circ} \mathrm{C}$, the peak heat transfer coefficients of $3088.99 \mathrm{~W} / \mathrm{m}^{2} \mathrm{~K}$, $3249.84 \mathrm{~W} / \mathrm{m}^{2} \mathrm{~K}$ and $2982.60 \mathrm{~W} / \mathrm{m}^{2} \mathrm{~K}$ are obtained for experimental, heat differential and method of semi-empirical equations as shown on figure 16 following the same pattern as in figure 15.

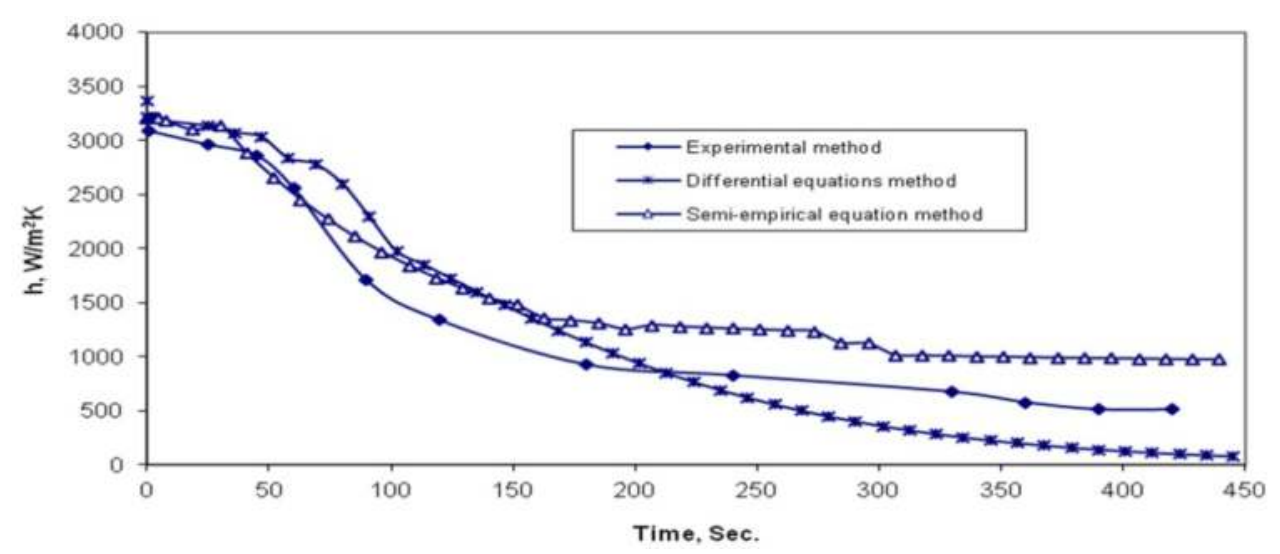

Figure 15. Typical comparison of numerical values of interface heat transfer coefficients with experimental and empirical values with pressure application $(\mathrm{P}=85.86 \mathrm{MPa}, \mathrm{TM}=300 \mathrm{C})$

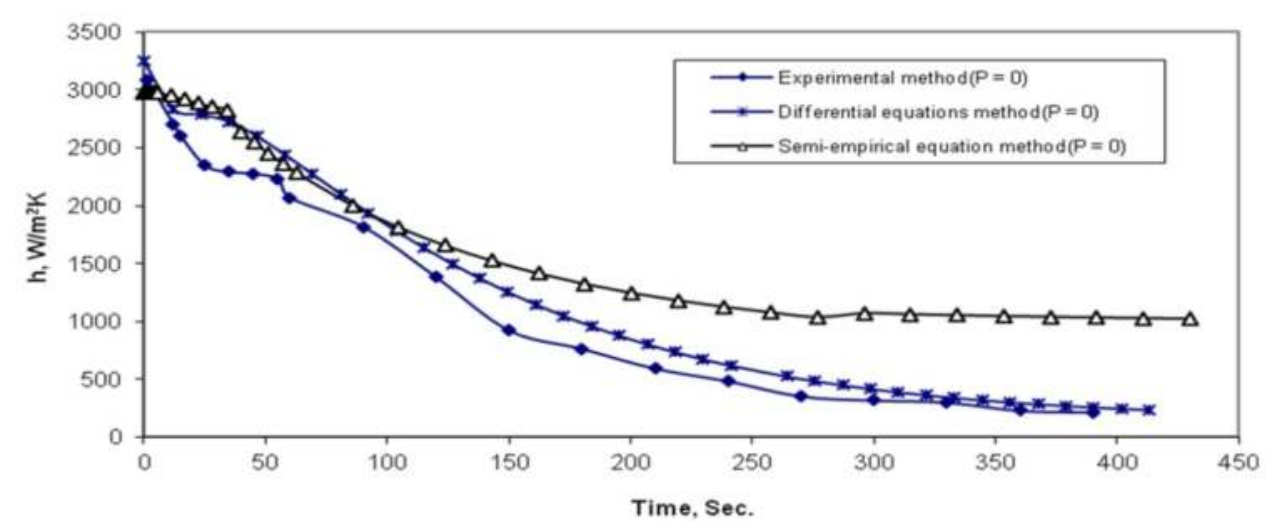

Figure 16. Typical comparison of numerical values of interface heat transfer coefficients with experimental and empirical values with die heating $\left(\mathrm{TM}=150^{\circ} \mathrm{C}\right)$ 


\section{Conclusions}

The following conclusions can be made from the present investigation:

The graph of temperature against time curves obtained by extrapolating to steel mould / cast metal interface by polynomial curve fitting to heating temperatures graphs with times at various steel mould locations are found to agree in values to the usual numerical methods obtained by previous authors. The interface heat transfer coefficients obtained by the numerical and experimental methods without the application of pressure are found to have values close to that of the numerical methods. The values of the numerical methods were higher by about $19.83 \%$.

Effect of pressure application on the solidifying molten aluminium is more pronounced at casting temperatures above $500^{\circ} \mathrm{C}$ of the cast aluminium specimen on the values of the interface heat transfer coefficients obtained. Interface heat transfer coefficients are found to decrease with increase in solidification time in both the cylindrical and bottom flat surfaces of the steel mould and thereafter remain fairly constant at temperature below $500^{\circ} \mathrm{C}$

Values of experimental peak heat transfer coefficients at the bottom flat surface are found to be higher with pressure application on the solidifying aluminium metal than at the cylindrical surface.

The empirical equations, relating the values of interface heat transfer coefficients with the applied pressures and solidification temperatures at three distinct stages of solidifying molten aluminium are determined and can be applied to determine the heat transfer coefficients.

The values of heat transfer coefficients obtained by heat differential equations incorporating internal heat energy and methods of semi-empirical equations are very close in values. The values as obtained by semi-empirical equations were higher by about $1.7 \%$ within the first 5 seconds of solidification.

The semi-empirical equations generated are flexible and could be used to predict the casting temperatures of other metals if the heat transfer coefficient values at the three phase changes are known.

\section{Nomenclature}

$\mathrm{C}_{\mathrm{L}} \quad$-Specific heat of liquid molten aluminium metal,

Cs $\quad$-Specific heat of solidified molten aluminium metal,

Cst - Specific heat of steel mould,

$\mathrm{d}_{\mathrm{sc}} \quad$-Spatial step size in the solidified molten metal at completion of solidification,

$d_{L} \quad-S p a t i a l$ step sizes at the Liquid portion,

dPs -Spatial step size at the solidified molten metal phase change,

dPL -Spatial step size at the solidified molten metal phase change,

$\mathrm{d}_{\mathrm{s}} \quad$-Spatial step size in the solidified molten metal,

ho -Initial height of cast specimen metal (no pressure application), 
hPL -Spatial step size at the liquid molten metal phase change,

hPs -Spatial step size at the solidified molten metal phase change,

$\mathrm{H}^{*} \quad$-Convective heat transfer of the surrounding atmosphere around the steel mould,

I -grid point,

G -grid point at the steel mould-solidified molten metal interface,

M -grid point at the solidified molten metal-liquid molten metal interface,

$\mathrm{N} \quad$-grid point at the centre of the solidifying cast specimen metal,

$\mathrm{K}_{\mathrm{L}} \quad$-Thermal conductivity of liquid molten metal,

Kst $\quad$-Thermal conductivity of steel mould material,

Ks -Thermal conductivity of solidified molten metal,

Ro - external radius of steel mould,

L -internal radius of steel mould,

$\mathrm{r} \quad$-radial axis/coordinate,

T -Temperature,

$\mathrm{T}_{\infty} \quad$-ambient temperature,

$\mathrm{T}_{\mathrm{i}} \quad$-temperature at a specified grid point $(\mathrm{i}, \mathrm{j})$,

$\mathrm{T}_{\mathrm{L}} \quad$-temperature of liquid molten metal,

$\mathrm{T}_{\mathrm{st}}, \mathrm{T}_{\mathrm{M}} \quad$-temperature of steel mould,

Tмм -melting temperature of cast (aluminium) metal,

$\mathrm{T}_{\mathrm{p}} \quad$-pouring temperature of liquid molten metal (super heat temperature),

Ts $\quad$-temperature of solidified molten metal,

$\mathrm{X}_{\mathrm{i}_{\mathrm{r}}} \quad$-thickness of solidified molten metal at a specified grid point-radial direction,

Q -Thickness of the cylindrical steel mould.

\section{Greek symbols}

$\alpha_{\mathrm{L}} \quad$-thermal diffusivity of the liquid molten metal,

$\alpha_{\text {st }} \quad$-thermal diffusivity of the steel mould material,

as -thermal diffusivity of solidified molten metal,

$\delta \quad$-time interval step,

$\rho_{\text {st }} \quad$-density of steel mould material,

ps -density of solidified molten metal,

$\rho \mathrm{L} \quad$-density of liquid molten metal,

$\sigma_{(\mathrm{T})} \quad$-Plastic flow stress (temperature dependent).

\section{Author details}

Jacob O. Aweda and Michael B. Adeyemi

Department of Mechanical Engineering, University of Ilorin, Ilorin, Nigeria

\section{References}

Adams, J. Alan \& Rogers, David F., (1973), "Computer Aided Heat Transfer Analysis”, McGraw-Hill Publishing Company, Tokyo. 
Bayazitoglu, Yildiz and Ozisik, M. Necati, (1988), “Elements of Heat Transfer”, McGraw-Hill Book Company, New York.

Beck J.V., (1970), “Nonlinear Estimation Applied to the Nonlinear Inverse Heat Conduction Problem", Int. J. Heat Mass Transfer, vol.13, pp703-716.

Bolton, W., (1989), “Engineering Materials Technology", Butterworths-Heinemann Limited, UK.

Browne, David J. and O'Mahoney, D., (2001), “Interface Heat Transfer in Investment casting of Aluminium", Metallurgical and Materials Transactions A, Dec. Vol.32A, pp30553063.

Callister, William D. Jr., (1997), "Materials Science and Engineering: An Introduction", $4^{\text {th }}$ Edition, John Wiley and Sons Inc.

Chattopadhyay, Himadri, (2007), "Simulation of transport process in squeeze casting", J. Materials Processing Technology, 186, pp174-178.

Cho I. S. and Hong C. P., (1996), "Evaluation of Heat-Transfer Coefficients at the Casting/Die Interface in Squeeze Casting", Int. J. Cast Metals Res., v.9, pp227-232.

Das A., and Chatterjee S. (1981), "Squeeze Casting of an Aluminium Alloy Containing Small Amount of Silicon Carbide Whiskers", The Metallurgist and Materials Technologist, pp137-142.

Elliott, R., (1988), “Cast Iron Technology”, Butterworths, London, U.K.

Gafur, M.A., Nasrul Haque and K. Narayan Prabhu, (2003), "Effects of chill Thickness and Superheat on Casting/Chill Interfacial Heat Transfer During Solidification of Commercially Pure Aluminium", J Materials Processing Technology, 133, pp257-265.

Hearn, E.J. (1992), "Mechanics of Materials", $2^{\text {nd }}$ Edition, Pergamon Press, UK.

Higgins, Raymon A., (1983), "Engineering Metallurgy Part I: Applied Physical Metallurgy", $6^{\text {th }}$ Edition, ELBS with Edward Arnold, UK.

Hosford, William F. and Caddell, Robert M., (1993), “Metal Forming, Mechanics and Metallurgy", $2^{\text {nd }}$ edition, PTR Prentice-Hall Englewood, NJ.

$\mathrm{Hu} \mathrm{H}$, and $\mathrm{Yu}$, A., (2002), "Numerical simulation of squeeze cast magnesium alloy AZ91D”, Modelling Simul. Mater Sci. Eng., vol.10, pp1-11.

Incropera, Frank P. and Dewitt, David P., (1985), "Fundamental of Heat and Mass Transfer", $3^{\text {rd }}$ Edition, John Wiley and Sons, NY.

Janna, William S., (1988), “Engineering Heat Transfer”, SI Edition, Van Nostrand Reinhold (International0, U.K.

Kim, T.G. and Lee, Z.H. (1997), Time-varying heat transfer coefficients between tube-shaped casting and metal mold, Int J, heat mass transfer, 40(15), pp3513-3525.

Kobryn P.A. and Semiatin S. L., (2000), “Determination of Interface Heat-Transfer Coefficients for Permanent Mold casting of Ti-6AL-4v", Metallurgical and materials Transactions, August, Vol.32B, pp685-695.

Liu, A., Voth, T. E. and Bergman, T. L., (1993), “Pure Material Melting and Solidification with Liquid Phase Buoyancy and Surface Tension Forces", Int. J. Heat Mass Transfer, Vol.36 No 2, pp441-442. 
Maleki, A., Niroumand, B. and Shafyei, A, (2006), “Effects of squeeze casting parameters on density, macrostructure and hardness of LM13 alloy", Materials Science and Engineering A, 428 pp135-140.

Martorano M. A. and Capocchi J.D.T., (2000), “Heat Transfer Coefficient at the Metal-Mold Interface in the Unidirectional Solidification of Cu-8\%Sn alloys", Intl J. Heat Mass Transfer, 43, pp2541-2552.

Ozisik, M. Necati, (1985), “Heat Transfer: - A Basic Approach”, McGraw-Hill Publishing, Company U.K.

Potter, D.A. \& Easterling, K.E., (1993), "Phase Transformations in Metals", 2 ${ }^{\text {nd }}$ Edition, Chapman \& Hall, London.

Reed-Hill, R E. and Abbaschian, R., (1973), “Physical Metallurgy Principles", $3^{\text {rd }}$ Edition, PWS-KENT Publishing Company, Boston.

Santos, C.A., Quaresma, J.M.V. and Garcia, A., (2001), “Determination of Transient Heat Transfer Coefficients in Chill Mold Castings", Journal of Alloys and Compounds, 139, pp 174-186.

Santos, C.A., Garcia, A., Frick, C.R and Spim J.A., (2004), "Evaluation of heat transfer coefficients along the secondary cooling zones in the continuous casting of steel billets, Inverse problems, Design and Optimization symposium", Rio de Janeiro, pp1-8

Shampire, Lawrence F., (1994), "Numerical Solution of Ordinary Differential Equations", Chapman \& Hall, New York.

White, Frank M., ( 1991), "Heat and Mass Transfer", Addison Wesley Publishing Company, Massachusetts. 